\title{
Influence of Convectively Coupled Equatorial Kelvin Waves on March-May Precipitation over East Africa
}

\author{
Phillip Okello Ochieng ${ }^{A B^{*}}$, GuirongTan ${ }^{A}$, Victor Ongoma ${ }^{C}$, Isaiah Nyandega ${ }^{D}$ \\ Received: October 08, 2020 | Revised: March 18, 2021 | Accepted: March 21, 2021 \\ doi: 10.5937/gp25-31132
}

\begin{abstract}
Convectively coupled equatorial Kelvin waves (CCEKWs) are those types of equatorially trapped disturbances that propagate eastward and are among the most commonintra-seasonal oscillations in the tropics. There existstwo-way feedback between the inter-tropical convergence zone (ITCZ) and these equatorially trapped disturbances. Outgoing Longwave Radiation (OLR) was utilized as a proxy for deep convection. For CCEKWs, the modes are located over the West Atlantic, equatorial West Africa, and the Indian Ocean. The influence of other circulations and climate dynamics is studied for finding other drivers of climate within East Africa. The results show a positive relationship between Indian and Atlantic Oceans Sea Surface Temperatures and March-May rainfall over equatorial East Africa over the period of 1980 to 2010. This influence is driven by the Walker circulation and anomalous moisture influx enhanced by winds. Composite analysis reveals strong lower-tropospheric westerlies during the active phase of the CCKWs activities over Equatorial East Africa. The winds are in the opposite direction with the upper-tropospheric winds, which are easterlies. Singular Value Decomposition shows a strong coupling interaction between rainfall over equatorial East Africa and CCKWs. This study concludes that Kelvin waves are not the main factors that influence rainfall during the rainy season. Previous studies show that the main influencing factors are ITCZ, El-Nino Southern Oscillation (ENSO), and tropical anticyclones that borders the African continent. However, CCKWs are a significant factor during the dry seasons.
\end{abstract}

Keywords: Convectively Coupled Equatorial Kelvin Waves; Inter-Tropical Convergence Zone; Singular Value Decomposition; East Africa; Precipitation

\section{Introduction}

The importance of rainfall over East Africa cannot be underscored. Unfortunately, the rain exhibits high spatial andtemporal variability. Most of the recent studies in the region (Cattani et al., 2018; Ongoma \& Chen, 2017) have focused on the past and future variability of rainfall, giving very little attention to the fac- tors that modulate the rainfall. Pohl and Camberlin (2006a; 2006b) had reported a more significant effect of ISOs influence on the long rains. Pohl and Camberlin (2006b) described Phases 2 and 3 from the Wheeler-Hendon index, when the convective core is over, using the Intra-Seasonal Oscillations phases established

\footnotetext{
A Collaborative Innovation Center on Forecast and Evaluation of Meteorological Disasters, Key Laboratory of Meteorological Disaster, Ministry of Education, Nanjing University of information Science and Technology, China; tanguirong@nuist.edu.cn

B Kenya Meteorological Services, Nairobi, Kenya

C University of the South Pacific, Fiji; victor.ongoma@gmail.com

D University of Nairobi, Department of Geography and Environmental Studies, Kenya; ianyandega@uonbi.ac.ke

* Corresponding Author: Phillip Okello Ochieng; e-mail: koderaphillips@yahoo.com
} 
by Wheeler and Hendon (2004). Enhanced precipitation over the East African mountains has been associated to Africa and the Indian Ocean.

Convectively coupled Kelvin Waves (CCKWs) are high-frequency intra-seasonal oscillations that extend eastward. They are perhaps among the most critical modes of variability that modulate rainfall in the tropics. They occur along with tropical cyclones and a much broader and smaller Madden - Julian oscillation (MJO) frequency. The movement of heat, humidity, and momentum varies greatly from within and outside the Intertropical Convergence Zone (ITCZ) due to enhanced convection and rainfall, which also affect circulation inside the tropics.

An analysis by Matsuno (1966) documented the near the equator confinement of wider-scale wavelike fluctuations by developing a complete collection of linear wave-mode approaches for shallow water equations upon this equatorial $\beta$-plane. Explicitly, this principle of tropical waves starts with the distinction of simple equations, linearized about a primitive state without a vertical shear, which regulates small movements in a three-dimensional stratum atmosphere on an equatorial $\beta$-plane, the 'vertical structure' formula and the 'shallow water' equations (LINDZEN, 1967; Matsuno, 1966).

The zonally (and vertically) propagating, equatorially trapped solutions of the shallow water equations are the equatorial wave modes defined by four parameters: number of the meridional mode, frequency, planetary zonal wavenumber, and 'equivalent depth of the' shallow 'fluid layer.The relative depth is connected to the velocity of the internal gravity wave as a segregation parameter that determines the vertical equation of the structure and the equations of shallow water. Thus, it is also linked to the vertical wavelength of free (dry) waves and the transverse progression by the equatorial Rossby radius relationship.

The hypothetical dissipation relationship will completely characterize and specify the wave provided by the southern mode number and wave category. Tropical waves are generally assumed to be forced by, and those regulating the natural convection are internal modes with structural elements similar to waves.

These waves produce the highest amplitude signals in outgoing longwave radiation (OLR) data near the equator (Roundy, 2008; Straub \& Kiladis, 2002; M. Wheeler \& Kiladis, 1999). MacRitchie \& Roundy (2012) showed that approximately 62 percent of the precipitation occurring in the negative OLR anomalies of the MJO between $10 \mathrm{oN}$ and $10 \mathrm{oS}$ over the IndoPacific warm pool areas occurs within the negative OLR anomalies of the Kelvin wave band.The result is nearly twice the average precipitation rate per unit area out of Kelvin waves, which is within the active MJO.

The skill of rainfall prediction over the Equatorial East African region falls below expectations most of the time. There is a need for further studies to understand the underlying physical systems that influence ITCZ displacement and, consequently, rainfall. The north-south oscillation of the ITCZ mainly affects the rainfall seasonality over the region. Thus, a discussion about rains over the area is incomplete without mentioning the ITCZ position in a given time. The main aim of this study was to determine the role of convectively coupled equatorial Kelvin waves and other circulation features on the precipitation over the Equatorial East African region. The results of the study aim to improve the on the accuracy of seasonal rainfall predictions which is very important for water resource management and agricultural productivity.

\section{Data and Methods}

\section{Study Area}

The study area was Equatorial African region located within the grid boxes $25^{\circ} \mathrm{E}-45^{\circ} \mathrm{E}$ and $5^{\circ} \mathrm{S}-5^{\circ} \mathrm{N}$. Although the region of interest is Equatorial East Africa, wave propagation is examined from as far as Atlantic Ocean through Equatorial West/East Africa to the Indian Ocean $\left(60^{\circ} \mathrm{W}\right.$ to $\left.120^{\circ} \mathrm{E}\right)$ to account for the potential wavelength of eastward propagating waves.

East Africa seasonal rainfall pattern is composed of two distinct seasons locally known as the long rains, occurring from March to May (MAM) with peak in April, and the short rains, taking place from October to December (OND) with peak in November as shown in figure.1c. While the long rains are associated with the relatively slow northward movement of the ITCZ, the short rains are related to a more rapid southward migration of this phenomenon (Walker et al., 2020). Thus, comparing precipitation events during the long rains season tend to be less variable, heavier, and longer in duration, with less interannual variability, and are more likely to be associated with local factors (Mutai \& Ward, 2000).

\section{Data}

The National Centers for Environmental Prediction (NCEP) and the National Center for Atmospheric Research (NCAR) have carried out a re-analyzed data project based on the Medium Range Forecast (MRF) model (Kalnay et al., 1996). This database is a re-analysis of the global observation network of weather pa- 
(a) MAM Mean Roinfall Distribution (1980-2010)

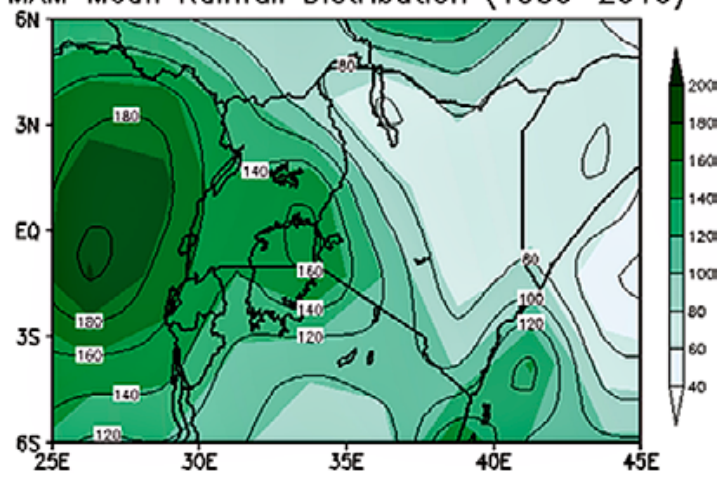

(b)

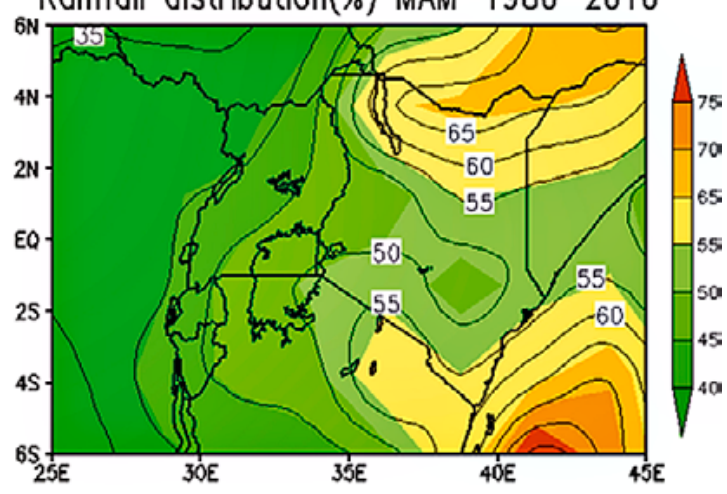

(c)

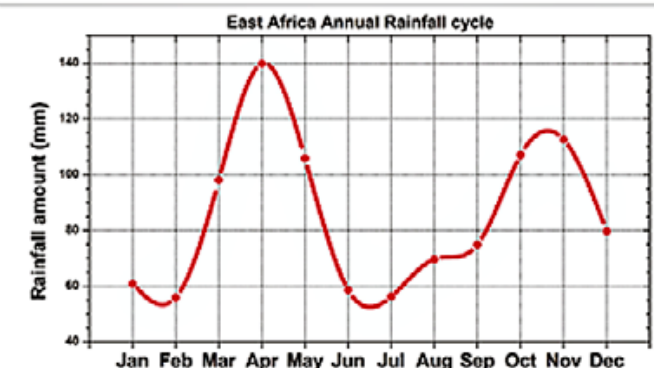

Figure 1. Study area showing the Climatology of MarchMay rainfall over Equatorial East Africa. a) MAM rainfall distribution in $\mathrm{mm} /$ month, b) Percentile distribution of rainfall over equatorial East Africa, c) Annual rainfall cycle of rainfall over equatorial East Africa in $\mathrm{mm} / \mathrm{month}$

rameters (wind, temperature, geo-potential height, pressure level humidity, surface area). The data runs from 1948 to the present. It is reported on a $2.5^{\circ} \mathrm{x} 2.5^{\circ}$ grid every six h $(00.00,06.00,12.00$, and 18.00 UTC), on 17 pressure levels from 1000 to $10 \mathrm{hPa}$, which are adequate resolutions for studying synoptic weather systems (Kalnay et al., 1996).

Outgoing Longwave Radiation (OLR) originates from the Environment Diagnostics Center (CDC). Data is typically collected twice daily from the National Oceanic and Atmospheric Administration (NOAA) polar-orbiting satellite (Gruber \& Krueger, 1984) and computed to daily values by Liebmann \&Smith (1996). ERA daily data involves the wind zone measured 4 times daily at 0000, 0600, 1200 and 1800 GMT. The data has a spatial resolutionof $2.5^{\circ} \times 2.5^{\circ}$ and, which covers the period 1980 to 2010 .

Tropical Rainfall Measuring Mission (TRMM) data has been used as a proxy for position and strength of ITCZ as rainfall is more closely related to convection. This data set spans from 1998 to the present on 3-hour $0.25^{\circ}$ latitudinal-longitude grid systems but has also been weighted for 6 -hour $1^{\circ}$ latitude-longitude meshes to increase statistical efficiency.TRMM precipitation dataset hasbeen applied by (Cho et al. 2004) to capture equatorial waves. TRMM product 3B42 (Huffman et al., 1997) is used in this study.

The Global Precipitation Climatology Project (GPCP) offers a reliable monthly estimate of global precipitation from the combination of different land and ocean satellite data sets and an overland gauge assessment (Adler et al., 2018). Data from rain sensor locations, satellites and sounding measurements have been combined to measure monthly rainfall on the global $2.5^{\circ}$ grid from 1979 to date. A detailed overview of the precipitation available to date across the global oceans provides an accurate integration of satellitebased rainfall estimates. It adds to the study of rainfall over land the required spatial information. Estimates of uncertainties in the rainfall analysis are provided as part of the GPCP items, in addition to the combination of these data sets.

\section{Methods}

\section{Wavenumber-frequency Filtering} and Wave power Spectral Analysis

The approach used in the first phase of this research is space-time spectrum analysis. This methodology is especially useful for the investigation of zonally moving waves as it decays a data field based on time and longitude into wavenumber and frequency elements for east and westward propagating waves and zone-average fluctuations (Hayashi, 1982). Because we are concerned about synoptic to intra - seasonal time frames, our key findings are centered on spec- tral amounts which have been determined for several consecutive overlap (by 60 days) of the 96-day sections of the multi-year OLR datasets. The findings are not responsive to such overlaps. To avoid spectral leakage, the first three seasonal cycle harmonics are excluded. During tapering, sophisticated fast Fourier Transforms (FFTs) is conducted in the longitude to determine the Fourier coefficients for each time and latitude. In order to achieve the wavenumber-frequency range for each latitude, additional FFTs are applied in time to these coefficients. 
Finally, the OLR power is distributed over all relevant sections of the 31-year period and is again added for latitudes between $15^{\circ} \mathrm{S}$ and $15^{\circ} \mathrm{N}$. The consequent effective bandwidth is $1 / 96$ cycles per day (cpd) in frequency and 1-unit zonal wavenumber. The overall number of degrees of freedom (dof), each latitude, and each (non-overlapping) 96-day section of the 31year period.

\section{Composite Analysis}

Composite assessment includes the detection and analysis of one or more sets of variables identified as per their relationship with essential conditions. The effects of the composites are then used to produce patterns that would hypothesize the phenomenon that could be correlated with individual scenarios.

A time series, hereafter called the CCKW index, was developed based on a selected grid point over equatorial East Africa $\left(0^{\circ} \mathrm{N}, 35^{\circ} \mathrm{E}\right)$. The CCKW index comprises all days where the minimum negative Kelvin-filtered OLR variance were less than -1.5 standard deviations as active phase and days where the maximum positive Kelvin-filtered OLR variance were more than +1.5 standard deviations as suppressed phase in magnitude during the 1980-2010 MAM seasons. Lags were then used on this time series in order to exam- ine propagating characteristics. Day 0 of the CCKW index was taken as the day when the minimum (maximum) Kelvin filtered OLR variance moves over the selected base point. This would show the evolution of precipitation when the various disturbances intensify/weaken.

\section{Singular Value Decomposition}

Singular value decomposition (SVD) has been widely used in meteorology since its first application by Prohaska (1976) to study the simultaneous relationships between surface air temperature over the United States of America and sea level pressure patterns. It requires no user-supplied parameters and lacks systematic bias. According to Bretherton et al. (1992) and Wallace et al. (1992), it is perhaps one of the preferable methods to directly produce explicit measures of the derived coupled patterns between two correlated fields.

SVD is a fundamental mathematical (matrix) operation that can be taken as an essential extension to rectangular matrices of square symmetric matrices' diagonalization. The cross-covariance matrix 's singular value decomposition identifies pairs of spatial patterns from two data fields that illustrate as much of the mean-squared temporal covariance between the two areas as possible.

\section{Results}

\section{Raw Background Power Spectral Analysis}

In order to investigate the convective variability associated with equatorial waves, spatial-time power spectral analysis is conducted. Power is shown in the antisymmetric and symmetric OLR components in figure.2. The most striking characteristic of these spectra in wavenumber and frequency isthe intensity of the red color. Notable variations can, however, be discerned between eastward and westward and symmetric and antisymmetric elements. The feature with the most power relative to the red background in either part or either propagating direction is the CCKWs, occurring mostly at eastward wavenumbers 2 to 10 , and centered at a period of about 2.5-20 days in OLRS, and to a lesser extent in OLR Antisymmetric spectrum. At frequencies less than about $0.3 \mathrm{cpd}$, there is a more significant occurrence of CCKWs in OLR Symmetric than OLR Anti-symmetric for almost all wavenumbers associated with the Kelvin waves.

Despite these general observed spectral features, the raw power spectra's detailed characteristics are likely to be obstructed by the spectrum's redness. For this reason, we defined a red background spectrum following Wheeler \& Kiladis (1999), which we then re- move from the original ranges, leaving the statistically significant spectral peaks as earlier explained.

The blue lines show filter bands, while the black lines show the dispersion curves of shallow water model Kelvin wave solutions at $=5 \mathrm{~m}$ and $90=\mathrm{m} \mathrm{su}-$ perimposed on a raw OLR spectrum. The findings are similar to those obtained by Wheeler and Kiladis (1999).
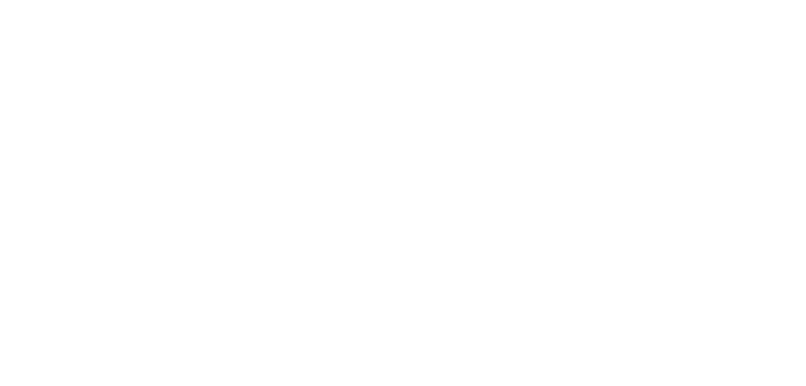

Figure 2. Wavenumber-frequency power spectrum of the symmetricand anti-symmetric componentof OLR for 1980-2010, summed from 15NN to 15오, and plotted as the ratio of the raw OLR power to the power in a smoothed red noise background spectrumduring MarchMay, where the signal is significant at greater than the 95\% level 


\section{The distribution of Kelvin filtered OLR variance}

The geographical distribution of the variance of Kelvin filtered OLR (averaged over 1980-2010 for MarchMay (MAM), which is the primary rainfall season over East Africa, is shown in figure.3. The overall activity is comparable to previous research findings employing OLR variance filtered for Kelvin waves (Mekonnen et al., 2008; Roundy \& Frank, 2004; M. Wheeler et al., 2000; M. Wheeler \& Kiladis, 1999). Over the equatorial Indian Ocean, the continent of tropical West Africa, and the central equatorial West Atlantic, peak activity occurs. The behavior of Kelvin waves is also commonly observed between $5^{\circ} \mathrm{S}-5^{\circ} \mathrm{N}$ over the entire tropical central-to-eastern Atlantic Oceans and $5^{\circ} \mathrm{S}-5^{\circ} \mathrm{N}$ to $30^{\circ} \mathrm{E}$ over West Africa. With the exception of tropical West Africa during the MAM season, the variance of Kelvin filtered OLR is not symmetrical with the equator, consistent with the previous Kelvin wave variance (Roundy \& Frank, 2004; Straub \& Kiladis, 2002). In MAM, the Kelvin wave is most dominant, with its spectral power concentrated, as predicted by linear theory, around the equator (Matsuno, 1966). Throughout the boreal summer, the Kelvin wave remains active, but its amplitude moves far away from the equator of the Northern Hemisphere. This offequatorial Kelvin wave maximum is correlated with the seasonal ITCZ migration.

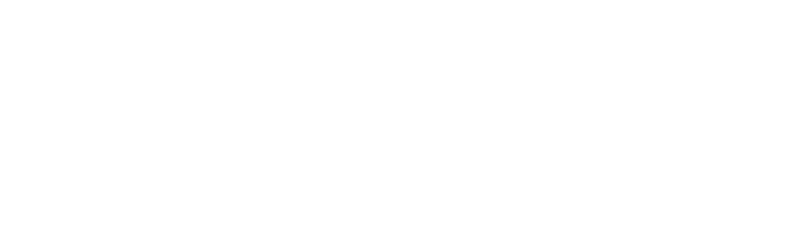

Figure 3. Geographical distribution of kelvin filtered OLR varianceduring MAM

\section{Upper Tropospheric Geopotential (100hPa)}

The most robust notable feature of CCKWs over the Western Hemisphere is their upper-level zonal wind signature and geopotential heightin figure.4. The upper tropospheric structure of the geopotential field shows an upper-level trough at lag0 days, which then disappears two days after the passage of the CCKWs. At lag-5 days before enacting the CCKWs over east Africa, an upper tropospheric ridge is located over the East Africa region. The rise seems to be quasi-stationary at lag- 5 to lag-2 days before shifting eastwards.

At lag-1 days (not shown), the ridge splits into two sections with the left one over South Atlantic Ocean and the equatorial Indian Ocean's right one. At lag+1 day, the upper-level ridge over the Indian Ocean disappears. Simultaneously, one over the Atlantic Ocean does not reach the east African region after the passage of the active phase of the CCKWs. The trough at lag0 days is slightly located to the west of the convec-

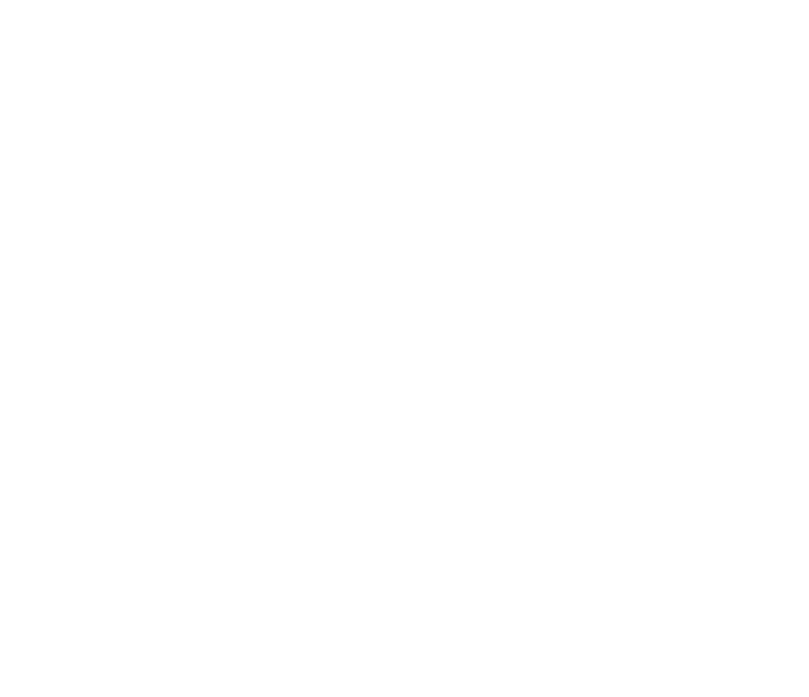

Figure 4. Lagged composites of the Upper Tropospheric Geopotential $(100 \mathrm{hPa})$ in meters on selected days based on the CCKW index. The shaded areas show regions significant at greater than $95 \%$ confidence level

tive area. Based on the findings in this section, the upper-tropospheric geopotential anomalies that intrude from the extra-tropics tend to force the initial convective anomaly associated with the Kelvin wave. Ventrice et al. (2012) obtained similar findings.

At lag0 days when the suppressed phases of CCKW, contrasting observations are made with the upperlevel ridge located on the same position as during the active phase. Similar polar observations are also made on other lag days.

\section{Upper-level Winds (200hPa)}

The complex structure of the CCKWs is defined, as shown in figure.5, by upper-level westerlies ahead of the CCKW convectively active period and upper-level easterlies eastward at lag0 days. For the convectively suppressed step of the CCKW, the reverse should therefore be right. It should be remembered that the CCKW-associated upper-level westerly wind anomalies create an atmosphere conducive to the infiltration of extra-tropical waves into the tropics. This corresponds with the results of Ventrice et al. (2012).

\section{Lower tropospheric Winds ( $850 \mathrm{hPa}$ )}

As the vector difference between $850 \mathrm{hPa}$ and 200 $\mathrm{hPa}$ levels, vertical wind shear is described. It is determined by averaging the CCKW index's set of dates. Composite analysis shows that vertical wind shear decreases before and after the CCKW's convectively active period passes over East Africa as anomalous westerly upper-level winds are opposite in flow with anomalous lower-level easterlies.The atmosphere is moistened by large-scale vertical motions associated with the convectively active process of the CCKWs. 


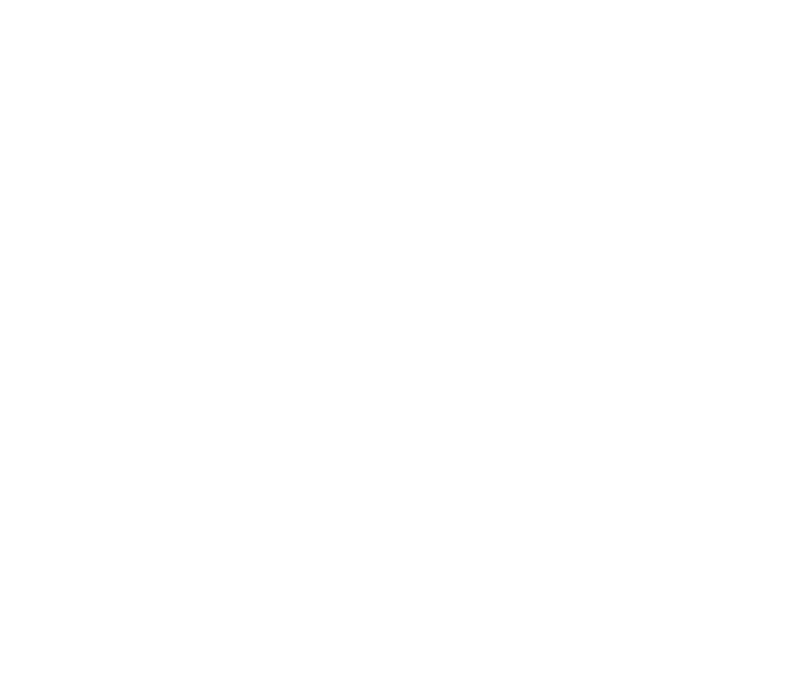

Figure 5. Lagged composites of the Upper Tropospheric winds $(200 \mathrm{hPa})$ in $\mathrm{m} / \mathrm{s}$ on selected days based on the CCKW index. The shadings show areas significant at greater than $95 \%$ level for easterly or westerly wind vectors

Figure. 6 indicates the vertical wind shear associated with the CCKWs' active and suppressed process.

Although CCKWs are typically associated with a wind structure at a lower level that is generally opposite to the flow of the upper troposphere, as seen in Figure.5, the zonal wind, temperature, and humidity of these waves have strongly tilted vertical structures (Mekonnen et al., 2008). The phase relationship between the structures of low-level and upper-level winds varies with the phase speed and zonal size of the wave.With the westerly flow at lower speeds, high pressure is collocated and low-pressure is collocated within the easterly flow. The inverse is true for the upper stages. Deep convection warms the mid-to-upper layers of the atmosphere and moistens them.

Over the Atlantic Ocean, the lower tropospheric winds are easterlies before the passage of the active phase of the CCKWs over East Africa. After the path, the winds are predominantly westerlies. The reverse is valid for the Indian Ocean basin. The $850-200 \mathrm{hPa}$ vertical wind shear exhibit the reverse patterns. Figure.6 shows the composites of the $850 \mathrm{hPa}$ winds on lagged days.

\section{Vertical motions}

Vertical motion tested for at over $90 \%$ confidence level is shown in Figure.7. At lag0 days, there exits ascending motions below 500-200 hPa thickness in the region over East Africa. On the other hand, there is a downward motion on the East Indian Ocean and the western Atlantic Ocean, which signifies a reverse walker circulation pattern. Similar patterns are observed at lag-1 days (not shown) before the passage of the active phase of Kelvin wave over East Africa. Of significance to note

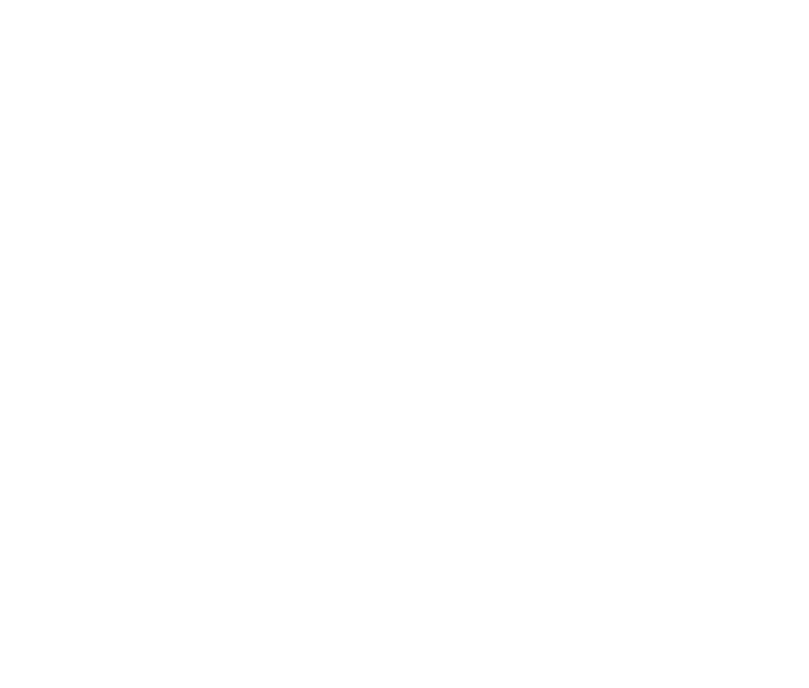

Figure 6. Lagged composites of the Lower Tropospheric $(850 \mathrm{hPa})$ winds $(\mathrm{m} / \mathrm{s})$ on the selected days based on the CCKW index (vectors). The shadings show areas significant at greater than $95 \%$ level for easterly or westerly wind vectors. Dashed contours represent regions with kelvin OLR variance greater than 400

is at lag-5 days. There is a similar motions pattern over the Atlantic, east Africa, and the Indian Ocean basin, downward motions over East Africa and Indian Ocean areas, and upward motion over East Atlantic.

The vertical motion extends to tropical central Africa at lag-5 days. The circulations associated with vertical movements are in the reverse directions at lag0 days compared to lag-5 days. This circulation pattern

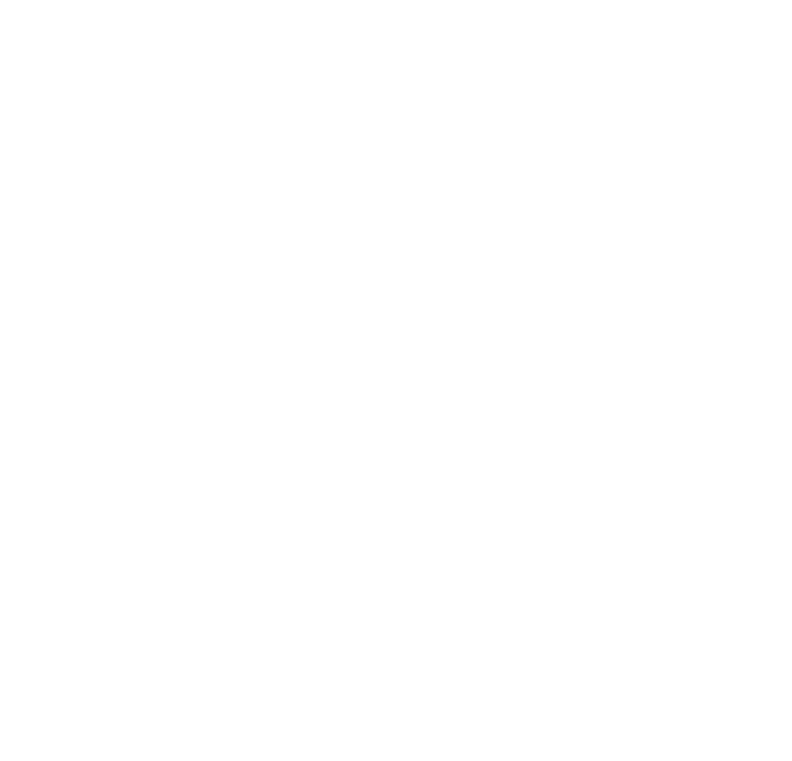

Figure 7. Lagged composites of the vertical cross section of the vertical motions (omega) in ( $\left.\mathrm{Pa} / \mathrm{s}^{*} 100\right)$ based on selected days of the CCKW index, left-active phase and right-suppressed phase. The black streamlines show the directions of the rising and sinking motions. The shadings show areas of significant vertical motion significant at over $80 \%$ confidence level 
is similar to the walker circulation, with descending and ascending motions over East Africa and the Indian Ocean. At lag +5 days there are opposite patterns of the vertical movements for the active and the suppressed phases of the CCKW events over the Atlantic and the Indian ocean basins with no significant motions as from lag +5 days.

The convergence of surface easterlies, which establish themselves in response to the geopotential height fields forced from the extra-tropics, is forced by lower tropospheric upward motion, as discussed earlier. The vertical motion anomalies confirm and spread across the depth of the troposphere as the Kelvin wave's coupled convective and dynamic fields disperse eastward.

\section{Temperature}

Figure 8 is a longitude-height cross-section of temperature (contours) with shadings showing regions tested for 95\% significance. During the active phase of the CCKWs at lag0 days, the troposphere is cooling up to $400 \mathrm{hPa}$ and warming between $300 \mathrm{hPa}$ and $200 \mathrm{hPa}$, and the tropopause is cold near and is locat-

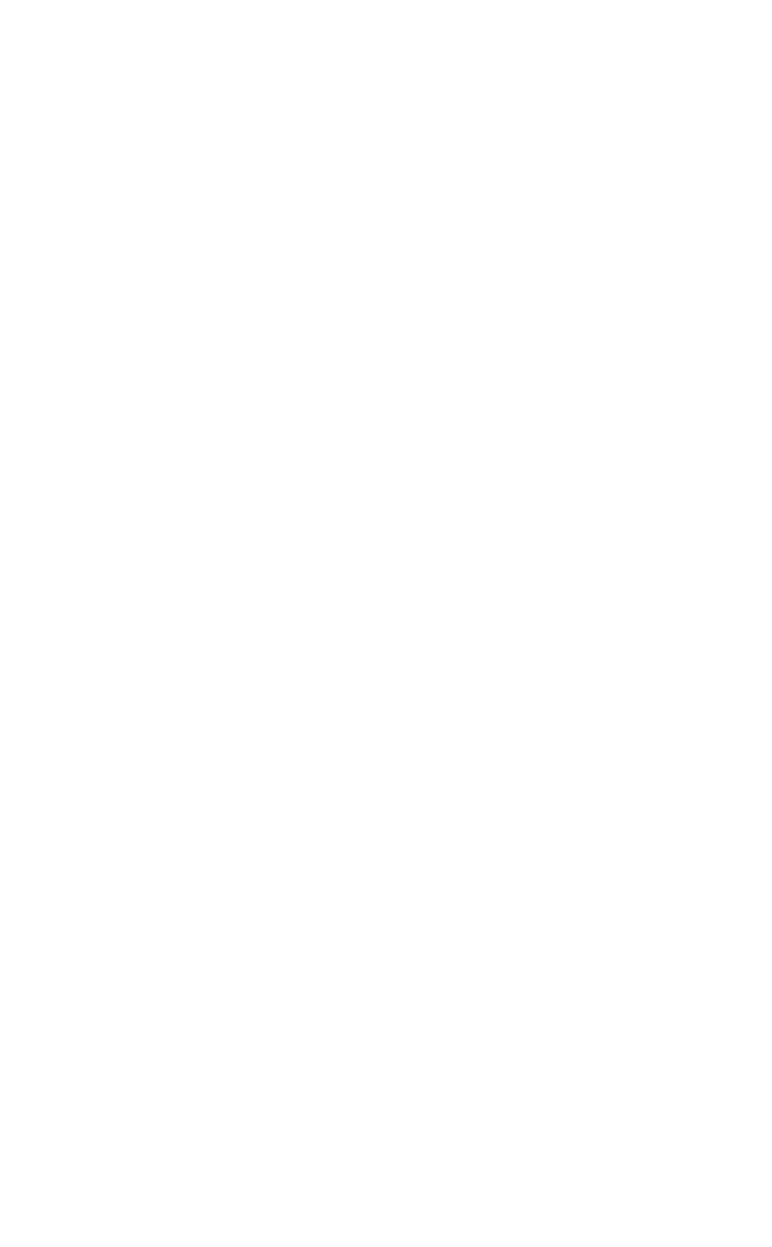

Figure 8. Composite of longitude-height section of air temperature ( contoured with shadings showing regions tested for $95 \%$ significance on the selected days based on CCKW index, left-active phase and right-suppressed phase ed near $100 \mathrm{hPa}$. This temperature profile is consistent with past findings (Wheeler and Kiladis 2000) of convectively coupled tropical waves. There is a warming of the entire troposphere and a cooling of the tropopause at lag- 3 and lag- 5 the day before the passing of the active period over East Africa.

The low and mid-level alternating heating and cooling observed during the lag0 days indicates that there is a tropospheric heat source that involves both deep convective heating and a second baroclinic heating mode over a cooling framework resulting from stratiform precipitation.The higher troposphere is colder and the sections of the lower troposphere and tropopause are warmer. The temperature response of the atmosphere to the convectively coupled Kelvin wave heating fields tends to be very linear, according to Wheeler et al. (2000). At lag+3 days after the passage of the active CCKW phase over East Africa, the troposphere tends to warm due to the latent heat release through convective heating and cooling at lag +5 days because of the latent heat dissipated during active convection triggered by CCKWs is no longer available within the environment.

Contrasting observations are made during the suppressed phase at lag0 days when the CCKW phase is over East Africa with cooling observed on the upper troposphere at 300-200 $\mathrm{hPa}$ levels an

\section{Singular Value Decomposition}

The three leading SVD modes of the coupled Kelvin Variance and Rainfall variations account for $74.67 \%$ of the total square covariance as shown in figure 9 and

(a) No.1 SVD field of MAM_KELVIN(1980-2010)

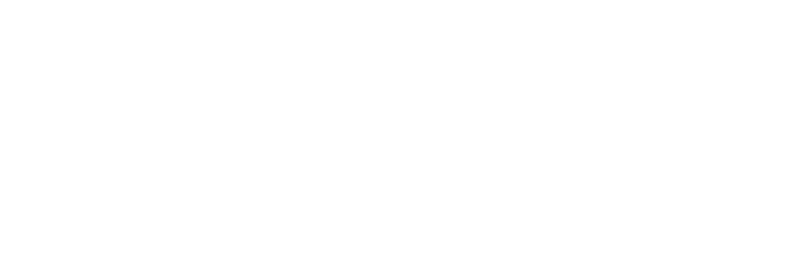

(b) No.2 SVD field of MAM_KELVIN(1980-2010)

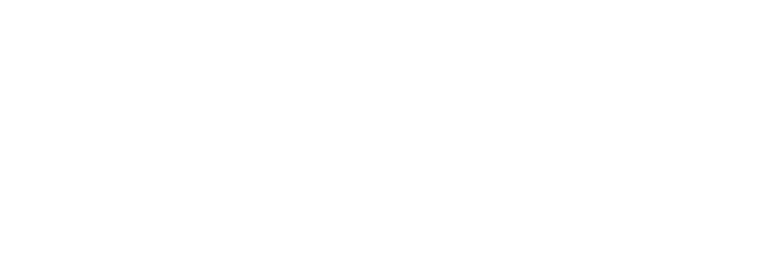

(c) No.3 SVD field of MAM_KELVIN(1980-2010)

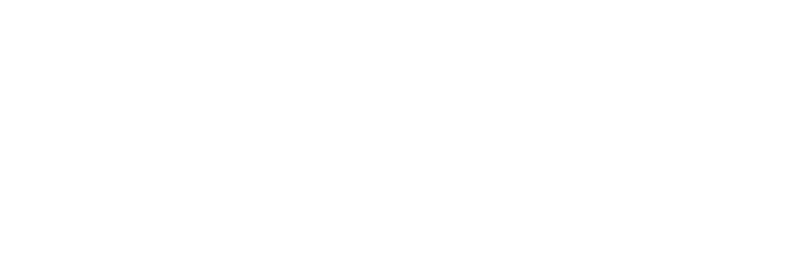

Figure 9. SVD fields of the MAM Kelvin variance. a) SVD1, b) SVD2, c) SVD3 joined lines shows area with positive spatial covariance, dotted lines show areas with negative spatial covariance and the zero contour is marked green 
Table 1. Square Covariance Fractions (SCF) explained by each mode and the correlation coefficient $(r)$

\begin{tabular}{|l|c|c|c|c|}
\hline Squared covariance & Fraction & Temporal Correlation & Kelvin Variance & Rainfall Variance \\
\hline Mode 1 & 37.76 & 0.54 & 22.64 & 21.01 \\
\hline Mode 2 & 28.79 & 0.55 & 16.61 & 21.04 \\
\hline Mode 3 & 8.72 & 0.77 & 7.40 & 7.46 \\
\hline
\end{tabular}

figure 10. For simplicity, I labeled the spatial patterns as SVDk, and the expansion coefficient as svdk, where $\mathrm{k}=1,2$ and 3 .

The square covariance fractions (SCF) explained by each mode and the correlation coefficient ( $\mathrm{r}$ ) between the expansion coefficients of the two svdk (Kelvin Variance) and svdk (rainfall)\} variables are shown in Table 1 as indicators of the coupling strength. The first mode has a substantial and extremely significant coupling variation of kelvin and rainfall in East Africa. Contrarily the correlation coefficient associated with the coupling of the modes increases. Although the least variance is demon- strated by the third SVD mode, its associated coupling coefficient is greater than those of the preceding modes, denoting the potential value of the third mode.

The first couple mode that dominates the variability between the March-May rainfall and the Kelvin variance reveals a positive monopole variability between kelvin variance over central Atlantic and Equatorial West Africa extending to the Indian Ocean basin, with substantial positive rainfall variability. The second couple mode that dominates the variability between the March-May rainfall and the kelvin variance reveals a negative monopole variability between
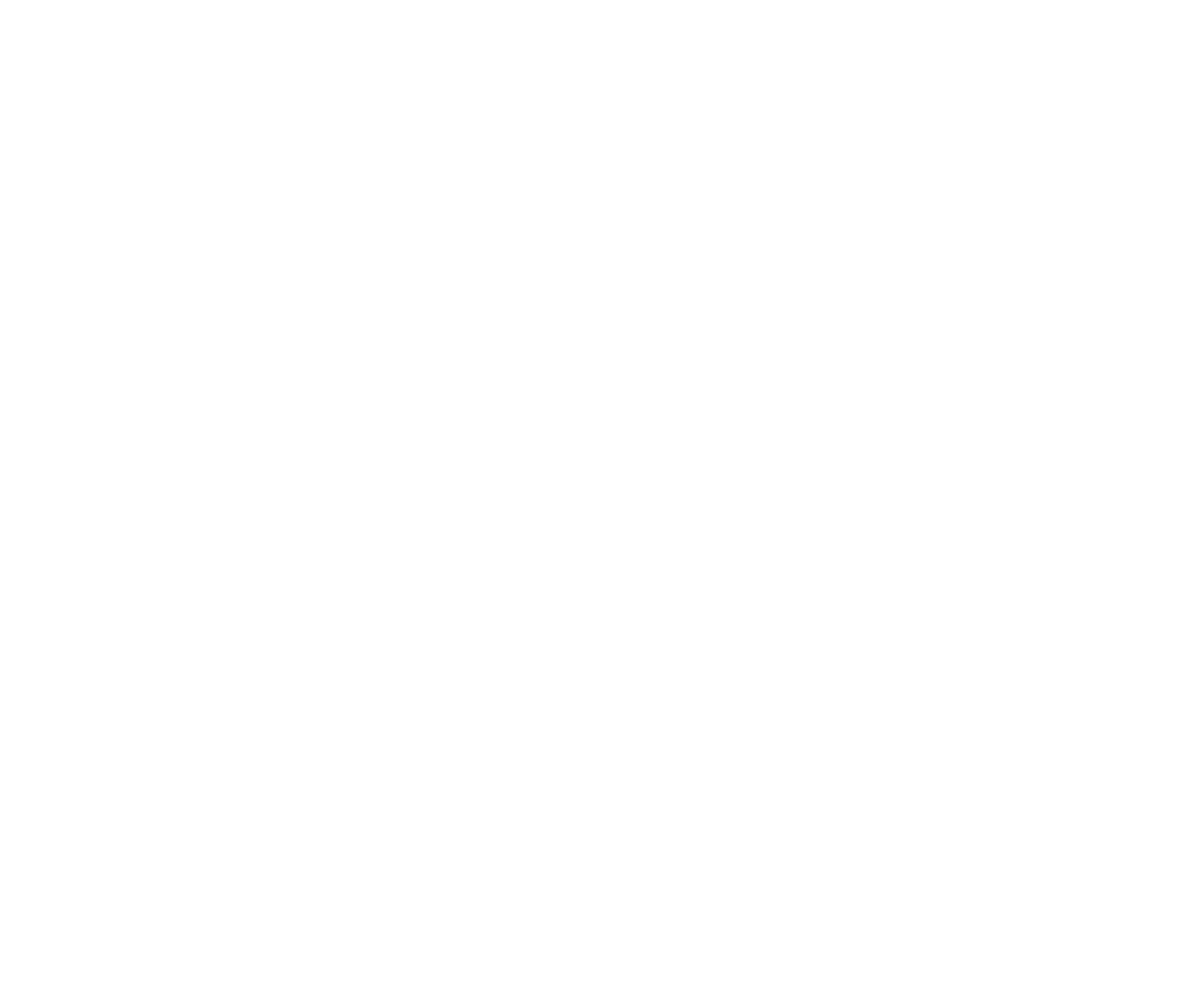

Figure 10. SVD fields of the MAM rainfall ( $\mathrm{mm} / \mathrm{month})$ over equatorial East Africa. a) SVD1, b) SVD2, c) SVD3. Red shading shows areas with positive spatial covariance and green shading shows areas with negative spatial covariance
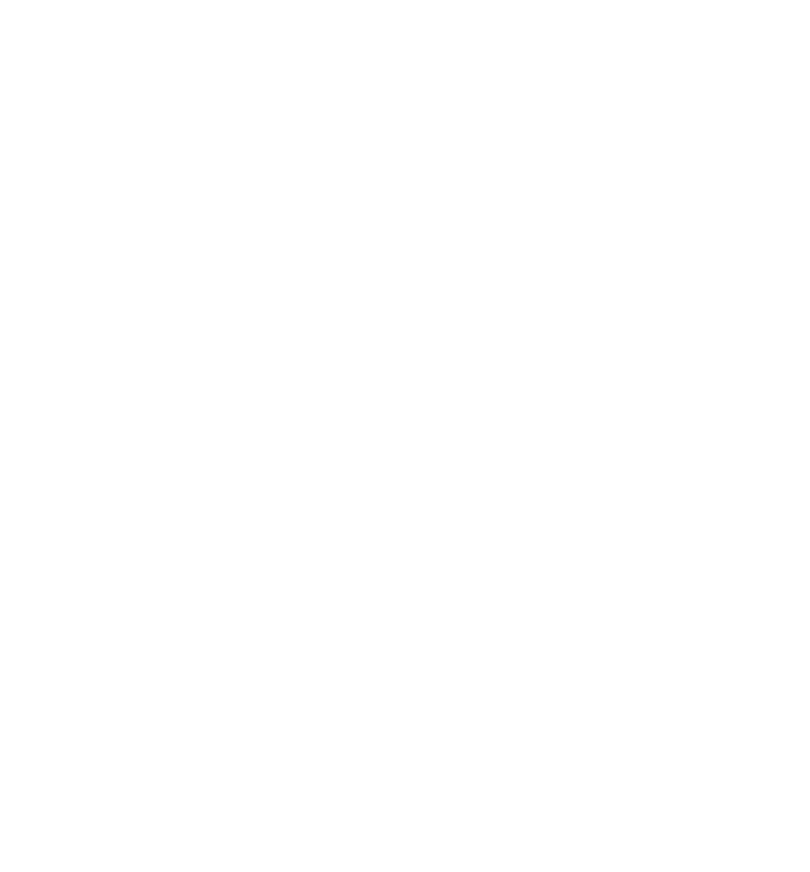

Figure 11. SVD temporal correlation between MAM Kelvin variance (black) and MAM rainfall ( $\mathrm{mm} /$ month) over equatorial East Africa (dotted-red). (a) SVD1, (b) SVD2, (c) SVD3 
Kelvin variance over central Atlantic and Equatorial West Africa extending to the Indian Ocean basin and reduced positive variability of rainfall. The temporal amplitude of rains and the Kelvin variance correlate very well $(>0.5)$, indicating the relationship's coupled nature as shown in figure 11 .

\section{Conclusion and Recommendations}

This work has focused on studying the dynamical variability in the entire troposphere up to the tropopause. Understanding the variability of this atmospheric layer on different temporal scales is very important before answering questions such as "Are there any eastward propagating disturbances from the Western Atlantic towards the African region?" or "Does NAO and Atlantic/Indian Ocean SSTs exert have any influence on rainfall over the Equatorial East African region?" can be answered.

A physical understanding of the environmental conditions that cause variability in the intra-seasonal oscillation in the tropics both vertically and horizontally can improve the accuracy of predictions of highfrequency rainfall over equatorial East Africa. These questions have been considered using the NOAA interpolated OLR and NOAA DOE datasets.

Over the equatorial Indian Ocean, the tropical continent of West Africa, and the central equatorial West Atlantic, peak CCKW activity occurs. The activity of Kelvin waves is also generally observed between $5^{\circ} \mathrm{S}$ $5^{\circ} \mathrm{N}$ over the entire tropical central-to-eastern Atlantic Oceans and between $5^{\circ} \mathrm{S}-5^{\circ} \mathrm{N}$ and $30^{\circ} \mathrm{E}$ over West Africa. Compared to other seasons, the CCWKs in MAM are stronger than in Equatorial East Africa.
SST warming near the equator Atlantic implies a conducive background scenario for the propagation of convectively coupled Kelvin waves. Increased SSTs in the Gulf of Guinea often lead in a weakened temperature gradient between the surface of the land and the sea, a characteristic of a weaker monsoon and decreased rainfall over tropical Africa, as shown in previous studies (Ward, 1998). The origin of the CCKWs over tropical Africa is also thought to be on the West tropical Atlantic, as proven by the correlation between Kelvin filtered OLR variance and SSTs. In agreement with Mekonnen et al. (2008), both the Atlantic and Indian Oceans have a positive correlation coefficient depicting a strong coupling between the indices and the rainfall over tropical east Africa.

The upper tropospheric and the lower tropospheric wind fields showed an opposite flow pattern with an upper-level trough seen on the day when the active phase of the CCKW is located over east Africa. This can be attributed to the strong easterly wind shear as observed in the active phase scenarios. CCKWs can also act as a triggering mechanism by enhancing conditions favorable for convection as it passes over a region.

\section{Acknowledgments}

The first author is grateful to the Ministry of Commerce of the People's Republic of China (MOFCOM) for sponsoring his MSc studies in China. The authors appreciate the contribution of all the data centers in providing the data free of charge.

\section{References}

Adler, R. F., Sapiano, M. R. P., Huffman, G. J., Wang, J. J., Gu, G., Bolvin, D., Chiu, L., Schneider, U., Becker, A., Nelkin, E., Xie, P., Ferraro, R., \& Shin, D. Bin. (2018). The Global Precipitation Climatology Project (GPCP) monthly analysis (New Version 2.3) and a review of 2017 global precipitation. Atmosphere, 9(4). https://doi.org/10.3390/atmos9040138

Barnston, A. G., \& Livezey, R. E. (1987). Classification, seasonality and persistence of low-frequency atmospheric circulation patterns. Monthly weather review, 115(6), 1083-1126. https://doi. org/10.1175/1520-0493(1987)115<1083:CSAPOL $>2$ $.0 . \mathrm{CO} ; 2$
Biasutti, M., Battisti, D. S., \& Sarachik, E. S. (2003). The annual cycle over the tropical Atlantic, south America, and Africa. Journal of Climate, 16(15), 2491-2508. https://doi.org/10.1175/15200442(2003)016<2491:TACOTT $>2.0 . C O ; 2$

Cattani, E., Merino, A., Guijarro, J. A., \& Levizzani, V. (2018). East Africa Rainfall trends and variability 1983-2015 using three long-term satellite products. Remote Sensing, 10(6), 1-26. https://doi. org/10.3390/rs10060931

Cattell, R. B. (1966). The scree test for the number of factors. Multivariate Behavioral Research, 1(2), 245276. https://doi.org/10.1207/s15327906mbr0102 10 
Chiang, J. C. H., Kushnir, Y., \& Zebiak, S. E. (2000). Interdecadal changes in castern Pacific ITCZ variability and its influence on the Atlantic ITCZ. Geophysical Research Letters, 27(22), 3687-3690. https://doi.org/10.1029/1999GL011268

Cho, H. K., Bowman, K. P., \& North, G. R. (2004). Equatorial waves including the Madden-Julian oscillation in TRMM rainfall and OLR data. Journal of Climate, 17(22), 4387-4406. https://doi. org/10.1175/3215.1

Convection-2-15Day.Pdf. (n.d.).

Dias, J., \& Pauluis, O. (2009). Convectively coupled waves propagating along an equatorial ITCZ. Journal of the Atmospheric Sciences, 66(8), 2237-2255. https://doi.org/10.1175/2009JAS3020.1

Emanuel, K. A., David Neelin, J., \& Bretherton, C. S. (1994). On large-scale circulations in convecting atmospheres. Quarterly Journal of the Royal Meteorological Society, 120(519), 1111-1143. https://doi. org/10.1256/smsqj.51901

Finney, D. L., Marsham, J. H., Walker, D. P., Birch, C. E., Woodhams, B. J., Jackson, L. S., \& Hardy, S. (2020). The effect of westerlies on East African rainfall and the associated role of tropical cyclones and the Madden-Julian Oscillation. Quarterly Journal of the Royal Meteorological Society, 146(727), 647664. https://doi.org/10.1002/qj.3698

Fu, R., Dickinson, R. E., Chen, M., \& Wang, H. (2001). How do tropical sea surface temperatures influence the seasonal distribution of precipitation in the equatorial Amazon? Journal of Climate, 14(20), 4003-4026. https://doi.org/10.1175/15200442(2001)014<4003:HDTSST $>2.0$. CO;2

Gruber, A., \& Krueger, A. F. (1984). The status of the NOAA outgoing longwave radiation data set. Bulletin - American Meteorological Society, 65(9), 958-962. https://doi.org/10.1175/15200477(1984)065<0958:TSOTNO >2.0.CO;2

Gu, G., \& Zhang, C. (2001). A spectrum analysis of synoptic-scale disturbances in the ITCZ. Journal of Climate, 14(12), 2725-2739. https://doi. org/10.1175/1520-0442(2001)014<2725:ASAOSS $>2$ $.0 . \mathrm{CO} ; 2$

Hayashi, Y. (1982). Space-Time Spectral Analysis and its Applications to Atmospheric Waves. Journal of the Meteorological Society of Japan. Ser. II, 60(1), 156-171. https://doi.org/10.2151/jmsj1965.60.1 156

Huang, B., Banzon, V. F., Freeman, E., Lawrimore, J., Liu, W., Peterson, T. C., Smith, T. M., Thorne, P. W., Woodruff, S. D., \& Zhang, H. M. (2015). Extended reconstructed sea surface temperature version 4 (ERSST.v4). Part I: Upgrades and intercomparisons. Journal of Climate, 28(3), 911-930. https://doi. org/10.1175/JCLI-D-14-00006.1
Huffman, G. J., Adler, R. F., Arkin, P., Chang, A., Ferraro, R., Gruber, A., Janowiak, J., McNab, A., Rudolf, B., \& Schneider, U. (1997). The Global Precipitation Climatology Project (GPCP) Combined Precipitation Dataset. Bulletin of the American Meteorological Society, 78(1), 5-20. https://doi. org/10.1175/1520-0477(1997)078<0005:TGPCPG $>2$ $.0 . \mathrm{CO} ; 2$

Kalnay, E., Kanamitsu, M., Kistler, R., Collins, W., Deaven, D., Gandin, L., Iredell, M., Saha, S., White, G., Woollen, J. \& Joseph, D. (1996). The NCEP/ NCAR 40-year reanalysis project. Bulletin of the American meteorological Society, 77(3), 437-472. https://doi.org/10.1175/1520-0477(1996)077<0437:TN YRP $>2.0 . C O ; 2$

Li, T., \& Philander, S. G. H. (1997). On the seasonal cycle of the equatorial Atlantic Ocean. Journal of Climate, 10(4), 813-817. https://doi.org/10.1175/15200442(1997) $010<0813:$ OTSCOT $>2.0 . C O ; 2$

Lindzen, R. D. (1967). Planetary Waves on Beta-Planes. Monthly Weather Review, 95(7), 441-451. https:// doi.org/10.1175/1520-0493(1967)095<0441:pwobp > 2.3.co;2

MacRitchie, K., \& Roundy, P. E. (2012). Potential vorticity accumulation following atmospheric Kelvin waves in the active convective region of the MJO. Journal of the Atmospheric Sciences, 69(3), 908-914. https://doi.org/10.1175/JAS-D-11-0231.1

Matsuno, T. (1966). Quasi-Geostrophic Motions in the Equatorial Area. Journal of the Meteorological Society of Japan. Ser. II, 44(1), 25-43. https://doi. org/10.2151/jmsj1965.44.1 25

Mekonnen, A., Thorncroft, C. D., \& Aiyyer, A. R. (2006). Analysis of convection and its association with African easterly waves. Journal of Climate, 19(20), 5405-5421. https://doi.org/10.1175/ ICLI3920.1

Mekonnen, A., Thorncroft, C. D., Aiyyer, A. R., \& Kiladis, G. N. (2008). Convectively coupled Kelvin waves over tropical Africa during the boreal summer: Structure and variability. Journal of Climate, 21(24), 6649-6667. https://doi. org/10.1175/2008JCLI2008.1

Mutai, C. C., \& Ward, M. N. (2000). East African rainfall and the tropical circulation/convection on intraseasonal to interannual timescales. Journal of Climate, 13(22), 3915-3939. https://doi. org/10.1175/1520-0442(2000)013<3915:EARATT> 2.0.CO;2

Ongoma, V., \& Chen, H. (2017). Temporal and spatial variability of temperature and precipitation over East Africa from 1951 to 2010. Meteorology and Atmospheric Physics, 129(2), 131-144. https:// doi.org/10.1007/s00703-016-0462-0 
Pohl, B., \& Camberlin, P. (2006a). Influence of the Madden-Julian Oscillation on East African rainfall. I: Intraseasonal variability and regional dependency. Quarterly Journal of the Royal Meteorological Society, 132(621), 2521-2539. https://doi. org/10.1256/qj.05.104

Pohl, B., \& Camberlin, P. (2006b). Influence of the Madden-Julian Oscillation on East African rainfall. II. March-May season extremes and interannual variability. Quarterly Journal of the Royal Meteorological Society, 132(621), 2541-2558. https:// doi.org/10.1256/qj.05.223

Kanamitsu, M., Ebisuzaki, W., Woollen, J., Yang, S. K., Hnilo, J. J., Fiorino, M., \& Potter, G. L. (2002). Ncep-doe amip-ii reanalysis ( $\mathrm{r}-2)$. Bulletin of the American Meteorological Society, 83(11), 1631-1644. https://doi.org/10.1175/BAMS-83-11

Roundy, P. E. (2008). Analysis of convectively coupled Kelvin waves in the Indian ocean MJO. Journal of the Atmospheric Sciences, 65(4), 1342-1359. https:// doi.org/10.1175/2007JAS2345.1

Roundy, P. E., \& Frank, W. M. (2004). A climatology of waves in the equatorial region. Journal of the Atmospheric Sciences, 61(17), 2105-2132. https://doi. org/10.1175/1520-0469(2004)061<2105:ACOWIT> 2.0.CO;2

Schreck, C. J., \& Molinari, J. (2011). Tropical cyclogenesis associated with Kelvin waves and the Madden-Julian oscillation. Monthly Weather Review, 139(9), 2723-2734. https://doi.org/10.1175/MWRD-10-05060.1

Straub, K. H., \& Kiladis, G. N. (2002). Observations of a convectively coupled Kelvin wave in the eastern Pacific ITCZ. Journal of the Atmospheric Sciences, 59(1), 30-53. https://doi.org/10.1175/15200469(2002)059<0030:OOACCK >2.0.CO;2

Ventrice, M. J., Thorncroft, C. D., \& Schreck, C. J. (2012). Impacts of convectively coupled kelvin- waves on environmental conditions for Atlantic tropical cyclogenesis. Monthly Weather Review, 140(7), 2198-2214. https://doi.org/10.1175/MWRD-11-00305.1

Walker, D. P., Marsham, J. H., Birch, C. E., Scaife, A. A., \& Finney, D. L. (2020). Common Mechanism for Interannual and Decadal Variability in the East African Long Rains. Geophysical Research Letters, 47(22). https://doi.org/10.1029/2020GL089182

Ward, M. N. (1998). Diagnosis and short-lead time prediction of summer rainfall in tropical North Africa at interannual and multidecadal timescales. Journal of Climate, 11(12), 3167-3191. https://doi. org/10.1175/1520-0442(1998)011<3167:DASLTP $>2$. $0 . \mathrm{CO} ; 2$

Wheeler, M. C., \& Hendon, H. H. (2004). An all-season real-time multivariate MJO index: Development of an index for monitoring and prediction. Monthly Weather Review, 132(8), 1917-1932. https://doi.org/10.1175/1520-0493(2004)132<1917:AA $\underline{\mathrm{RMMI}>2.0 . \mathrm{CO} ; 2}$

Wheeler, M., \& Kiladis, G. N. (1999). Convectively Coupled Equatorial Waves: Analysis of Clouds and Temperature in the Wavenumber-Frequency Domain. Journal of the Atmospheric Sciences, 56(3), 374-399. https://doi.org/10.1175/15200469(1999)056<0374:CCEWAO >2.0.CO;2

Wheeler, M., Kiladis, G. N., \& Webster, P. J. (2000). Large-scale dynamical fields associated with convectively coupled equatorial waves. Journal of the Atmospheric Sciences, 57(5), 613-640. https://doi. org/10.1175/1520-0469(2000)057<0613:LSDFAW >2 $.0 . \mathrm{CO} ; 2$

Zhou, L., Wang, S., Du, M., Chen, Q., He, C., Zhang, J., Zhu, Y., \& Gong, Y. (2021). The influence of ENSO and MJO on drought in different ecological geographic regions in China. Remote Sensing, 13(5), 1-19. https://doi.org/10.3390/rs13050875 